\title{
A Crossover Comparison of the Sensitivity and the Specificity between BIS and AEP in Predicting Unconsciousness in General Anesthesia
}

\author{
Haitao Yang $(\mathbb{D}$, Guan Wang $(\mathbb{D}$, Jinxia Gao $(\mathbb{D}$, and Jie Liu \\ Department of Anesthesiology, The Second Hospital of Dalian Medical University, Dalian 116027, China \\ Correspondence should be addressed to Jinxia Gao; gaojinxia2006@163.com and Jie Liu; liujaye@hotmail.com
}

Received 30 September 2020; Revised 27 November 2020; Accepted 18 December 2020; Published 29 December 2020

Academic Editor: Liang Zhao

Copyright (C) 2020 Haitao Yang et al. This is an open access article distributed under the Creative Commons Attribution License, which permits unrestricted use, distribution, and reproduction in any medium, provided the original work is properly cited.

\begin{abstract}
Background. There is an increasing concern of awareness and recall during general anesthesia for both the patient and the anesthetist. The bispectral index (BIS) is used to assess the level of sedation and depth of anesthesia and detect consciousness in different anesthetic drugs. Middle-latency auditory evoked potentials (AEPs) also quantify action of anesthetic drugs and detect the transition from consciousness to unconsciousness. We aim to compare the sensitivity and specificity between BIS and AEP in predicting unconsciousness in inhalational sevoflurane anesthesia and intravenous propofol anesthesia. Methods. Totally, 40 patients were randomly allocated into two groups: propofol or sevoflurane group. In the propofol group, anesthesia was induced with target-controlled infusion propofol. In the sevoflurane group, anesthesia was induced by increasing concentrations of sevoflurane. There were 3 end points during induction: sedation, unconsciousness, and anesthesia. Target and effect-site concentrations of propofol, end-tidal concentration of sevoflurane, and BIS and AEP were recorded at each stage. Results. We obtained good EC50 with both monitors, at which there is a 50\% chance that the patient has reached the end point, but the index variation was affected by the anesthetic technique. Propofol had higher correlations with stage of anesthesia, BIS, and AEP than sevoflurane. BIS had higher correlations with depth of anesthesia than AEP, but we did not find an anesthetic depth monitor that had high sensitivity and specificity and is not affected by the anesthetic technique. Conclusions. The prediction powers of BIS and AEP do not seem as good as some papers mentioned.
\end{abstract}

\section{Introduction}

Awareness and recall during general anesthesia, which are unintended accidental, represent failure of successful anesthesia and cause a serious complication of general anesthesia that is feared by patients and anesthetists alike [1-3]. It is difficult to describe and identify return to consciousness, so the reported incidence rates vary widely. Evidence suggests that the overall risk of awareness during anesthesia is between 0.1 and $0.5 \%[2,4-6]$, and awareness has been considered as a potentially important factor for the occurrence of some diseases in patients, such as severe emotional distress and posttraumatic stress disorder [4, 6-8]. It also has important professional, personal, and financial consequences for the anesthetists [8-11].
The bispectral index (BIS), derived from electroencephalogram, is the most commonly used and accepted monitor for assessing the level of sedation and depth of anesthesia [10, 12-15]. BIS predicts movement in response to surgery and detects consciousness under different anesthetic drugs [15-18]. It is also a tool that may reduce the incidence of unexpected recall $[10,12,13,18]$.

Middle-latency auditory evoked potentials (AEPs) also quantify the action of anesthetic drugs and detect the transition from consciousness to unconsciousness [19-23]. The AEP index (AEP) is a dimensionless number scaled from 100 (awake) to 0 and a mathematically derived variable measuring the amplitude and latency of the cortical midlatency auditory evoked potential that occurs in response to sound (a "click") [21, 23, 24]. 
Sevoflurane inhalational and propofol intravenous anesthesia are two widely used anesthetic techniques. However, there are no reports about the comparison of ability of predicting the awareness by BIS or AEP during these two anesthesia techniques. Herein, this study is designed to compare the sensitivity and the specificity between BIS and AEP in predicting unconsciousness with sevoflurane inhalational and propofol intravenous anesthesia.

\section{Materials and Methods}

The study was approved by the institutional review board. Unpremedicated patients who had given informed consent were recruited into the study. Demographic data and ASA classification were recorded. Routine monitoring plus monitoring for BIS and AEPi was established before the induction of anesthesia. Awake values for BIS and AEPi were recorded before the induction of anesthesia. Patients breathed oxygen through a standard anesthetic breathing circuit during induction. Patients were randomised into propofol or sevoflurane groups. There were 3 end points during induction:

(1) Sedation: patent was asleep and responded to gentle shaking or loud auditory stimulus (stage 4 of Ramsay scale).

(2) Loss of consciousness: patient showed no response to verbal command and loss of eyelash reflex.

(3) Anesthesia: patient gave no purposeful movement on tetanic stimulation to the ulnar nerve $(50 \mathrm{~Hz}, 80 \mathrm{~mA}$, $0.25 \mathrm{~ms}$ pulses) at the wrist using a constant current peripheral nerve stimulator.

The BIS and AEPi were recorded at each stage. In the propofol group, anesthesia was induced with target-controlled infusion (TCI) propofol. The TCI was initially set at $1 \mu \mathrm{g} \cdot \mathrm{l}^{-1}$ and increased by $0.5 \mu \mathrm{g} \cdot \mathrm{l}^{-1}$ every 2 minutes until anesthesia. Target and effect-site concentrations of propofol were recorded at each end point. In the sevoflurane group, anesthesia was induced by increasing concentrations of sevoflurane. End-tidal concentration of sevoflurane was recorded at each end point.

2.1. Anesthesia Induction. Routine monitoring plus monitoring for BIS and AEP was established before the induction of anesthesia. Awake values for BIS and AEP were recorded before the induction of anesthesia. Patients breathed oxygen through a standard anesthetic breathing circuit during induction. Patients were randomised into propofol or sevoflurane groups. There were 3 end points during induction: (1) sedation: patient was asleep and responded to gentle shaking or loud auditory stimulus (stage 4 of Ramsay scale); (2) unconsciousness: patient showed no response to verbal command and loss of eyelash reflex; (3) anesthesia: patient gave no purposeful movement on tetanic stimulation to the ulnar nerve ( $50 \mathrm{~Hz}, 80 \mathrm{~mA}, 0.25 \mathrm{~ms}$ pulses) at the wrist using a constant current peripheral nerve stimulator. The BIS and AEP were recorded at each stage. In the propofol group, anesthesia was induced with target-controlled infusion (TCI) of propofol. The TCI was initially set at $1 \mu \mathrm{g} \cdot 1^{-1}$ and increased by $0.5 \mu \mathrm{g} \cdot \mathrm{l}^{-1}$ every 2 minutes until anesthesia. Target and effect-site concentrations of propofol were recorded at each end point. In the sevoflurane group, anesthesia was induced by increasing concentrations of sevoflurane. End-tidal concentration of sevoflurane was recorded at each end point.

2.2. Statistical Analysis. GraphPad Prism version 5 (GraphPad Software, Inc) was used for data analysis. Demographic data were analyzed by the chi-square test and $t$-test. Haemodynamic data were analyzed by repeated measures analysis of variance and post hoc pair-wise comparison for difference stages of anesthesia. Spearman correlation analysis, logistic regression analysis, receiver operating characteristic (ROC) analysis, sensitivity and specificity, and prediction probability $\left(P_{K}\right)$ were used for analyzing the depth of anesthesia, drug concentration, BIS, and AEP. $P<0.05$ was considered to have statistically significant difference.

\section{Results}

3.1. Patient Characteristics. Forty-two patients were assessable for intraoperative BIS and AEP data, including 22 patients with sevoflurane anesthesia and 20 patients with propofol anesthesia. Two patients of the sevoflurane group were censored because of the unreasonable high BIS and AEP in the anesthesia stage. One patient of the sevoflurane group swapped the effect-site concentrations on sedation and unconsciousness because of the unreasonable high concentrations ( 4 and $4.6 \mathrm{mcg} / \mathrm{ml}$ ) in the sedation stage. No significant difference in gender, height, weight, smoking history, alcohol intake, pain in sedation stage, or American society of Anesthesiologists status was found between two groups (Table 1).

3.2. Haemodynamic Data. Systolic blood pressure (SBP), heart rate $(\mathrm{HR})$, and respiratory data (RR) in two groups were analyzed in four stages: base, sedation, unconsciousness, and anesthesia (Tables 2 and 3 and Figure 1).For SBP, time effect was significantly different at the 0.05 level of significance. Time and group interaction effect was significantly different at the 0.01 level of significance. On the propofol group, the SBP on all the other stages was significantly different from the baseline $(P=0.0003,<0.0001$, and $<0.0001$ in sedation, unconsciousness, and anesthesia stages, respectively). The SBP on the sedation stage was also significantly different from the SBP on the unconsciousness and anesthesia stages. On the sevoflurane group, the SBP on all the other stages was significantly different from the baseline ( $P=0.0354,0.0053$, and 0.0031 in sedation, unconsciousness, and anesthesia stages, respectively). The SBP on the sedation stage was significantly different from the SBP on unconsciousness and anesthesia stages.

On HR, both time effect and group interaction effects were significantly different at the 0.05 level of significance. On the propofol group, the heart rates on all the other stages were significantly different from the baseline heart rate 
TABLE 1: Patient characteristics.

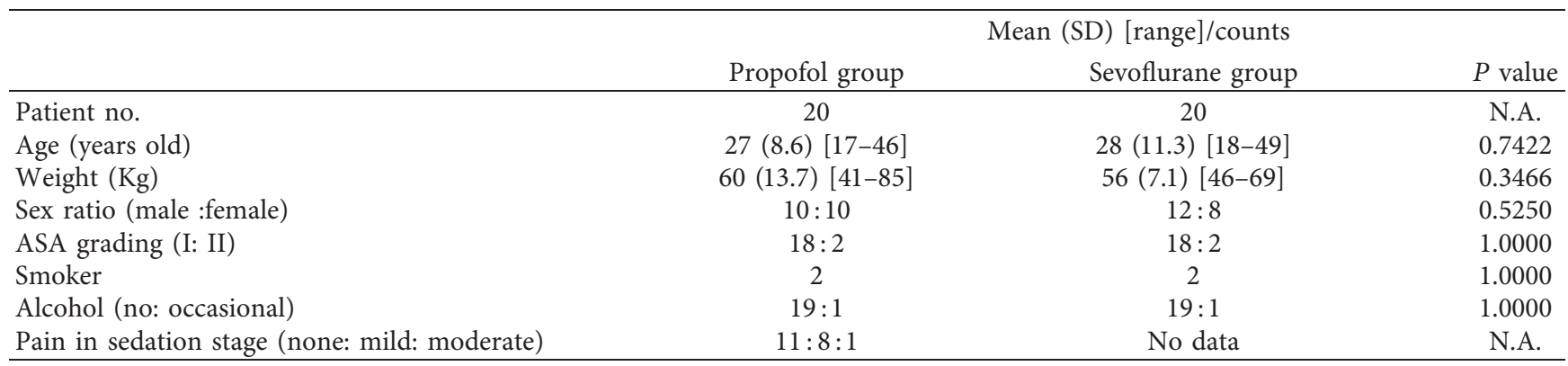

ASA, American society of Anesthesiologists; N.A., not applicable.

TABle 2: Haemodynamic data.

\begin{tabular}{|c|c|c|c|c|}
\hline & \multirow{2}{*}{ Stage } & \multicolumn{2}{|c|}{ Mean \pm SD } & \multirow{2}{*}{$P$ values } \\
\hline & & Propofol & Sevoflurane & \\
\hline \multirow{4}{*}{ Systolic blood pressure (SBP) in HHmg } & Base & $117.6 \pm 12.7$ & $117.1 \pm 15.3$ & \multirow{4}{*}{$\begin{array}{l}\text { Group: } 0.4542 \\
\text { Time: }<0.0001^{* *} \\
\text { Interact: } 0.0542\end{array}$} \\
\hline & Sed & $112.2 \pm 11.8$ & $112.5 \pm 11.1$ & \\
\hline & Uncon & $105.8 \pm 8.8$ & $109.4 \pm 10.4$ & \\
\hline & Anes & $102.0 \pm 7.4$ & $108.4 \pm 11.2$ & \\
\hline \multirow{4}{*}{ Heart rate $(\mathrm{HR})$ in beat $\min ^{-1}$} & Base & $80.5 \pm 10.7$ & $79.6 \pm 10.4$ & \multirow{4}{*}{$\begin{array}{c}\text { Group: } 0.0784 \\
\text { Time: } 0.0596 \\
\text { Interact: } 0.0118^{* *}\end{array}$} \\
\hline & Sed & $76.7 \pm 8.6$ & $81.0 \pm 11.4$ & \\
\hline & Uncon & $72.2 \pm 10.1$ & $79.2 \pm 13.1$ & \\
\hline & Anes & $72.9 \pm 11.7$ & $84.4 \pm 14.9$ & \\
\hline \multirow{4}{*}{ Respiratory rate (RR) in breaths $\min ^{-1}$} & Base & $18.3 \pm 3.2$ & $17.0 \pm 3.1$ & \multirow{4}{*}{$\begin{array}{c}\text { Group: } 0.0964 \\
\text { Time: } 0.4993 \\
\text { Interact: } 0.9212\end{array}$} \\
\hline & Sed & $17.9 \pm 2.6$ & $16.6 \pm 2.6$ & \\
\hline & Uncon & $18.2 \pm 2.4$ & $16.7 \pm 2.7$ & \\
\hline & Anes & $18.2 \pm 2.7$ & $17.1 \pm 2.7$ & \\
\hline
\end{tabular}

${ }^{* *}$ Significant at 0.05 . Notes: repeated measures analysis of variance was applied. Interact $=$ group ${ }^{*}$ time interaction effect.

Table 3: $P$ values for post hoc pair-wise comparisons.

\begin{tabular}{|c|c|c|c|}
\hline & \multicolumn{3}{|c|}{$P$ values } \\
\hline & Baseline & Sedation & Unconsciousness \\
\hline \multicolumn{4}{|l|}{ SBP } \\
\hline \multicolumn{4}{|c|}{ Time effect in propofol group } \\
\hline Sedation & $0.0003^{* *}$ & - & - \\
\hline Unconsciousness & $<.0001^{* *}$ & $<.0001^{* *}$ & - \\
\hline Anesthesia & $<.0001^{* *}$ & $0.0001^{* *}$ & 0.0167 \\
\hline \multicolumn{4}{|c|}{ Time effect in sevoflurane group } \\
\hline Sedation & 0.0354 & - & - \\
\hline Unconsciousness & $0.0053^{* *}$ & 0.0493 & - \\
\hline Anesthesia & $0.0031^{* *}$ & 0.0355 & 0.4102 \\
\hline \multicolumn{4}{|c|}{ HR } \\
\hline \multicolumn{4}{|c|}{ Time effect in propofol group } \\
\hline Sedation & 0.0266 & - & - \\
\hline Unconsciousness & $0.0034^{* *}$ & 0.0133 & - \\
\hline Anesthesia & 0.0188 & 0.0610 & 0.6775 \\
\hline \multicolumn{4}{|c|}{ Time effect in sevoflurane group } \\
\hline Sedation & 0.5275 & - & - \\
\hline Unconsciousness & 0.8083 & 0.1995 & - \\
\hline Anesthesia & 0.2306 & 0.1517 & $0.0122^{* *}$ \\
\hline
\end{tabular}

Adjusted $\alpha^{\prime}=0.0125(=0.05 / 4)$ for post hoc comparisons ${ }^{* *} P<0.01$.

$(P=0.0266,0.0034$, and 0.0188 in sedation, unconsciousness, and anesthesia stages, respectively). The heart rate on the sedation stage was also significantly different from the heart rate on the unconsciousness stage $(P=0.0133)$. On the sevoflurane group, there were not significantly different in all different stages.

\subsection{Drug Concentrations, BIS, and AEP}

3.3.1. Descriptive Statistics of Drug Concentrations, BIS, and AEP at Different Stages of Induction. redicted blood and effect-site propofol concentrations and inspired and endtidal sevoflurane concentrations during different stages of induction are shown in Table 4. Both BIS and AEP showed a trend of diminishing level of consciousness with both anesthetic techniques.

3.3.2. Correlation Analysis. On correlation analysis of BIS and AEP vs. propofol and sevoflurane concentration, only 6 correlation coefficients in the propofol group were significant at the 0.05 level of significance. $r=-0.50,-0.49$, and -0.45 when BIS is in the unconsciousness stage vs. predicted blood concentration of propofol in sedation, anesthesia stages, and effect-site concentration of propofol in the anesthesia stage, respectively. $r=0.56$ when AEP is in the anesthesia stage vs. predicted blood concentration and effect-site concentration of propofol in the unconsciousness stages, and $r=-0.53$ when AEP of baseline vs. effect-site concentration of propofol is in the sedation stage. They were around 0.5 , just fair correlated. All the others are not significantly correlated (Tables 5 and 6). On correlation analysis 


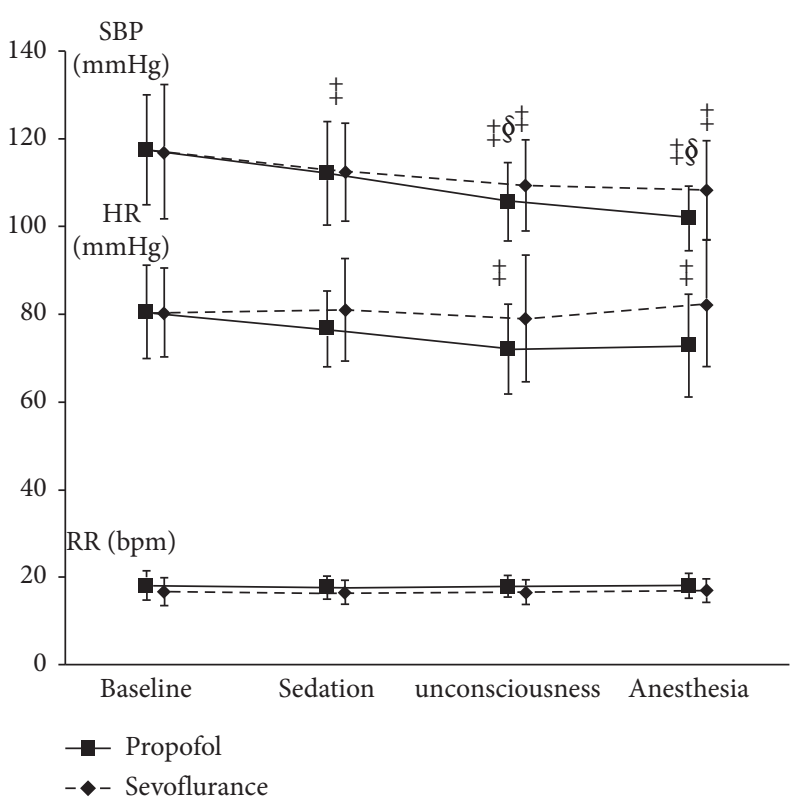

FIGURE 1: Systolic blood pressure (SBP), heart rate (HR), and respiratory data (RR) of two groups in four stages: base, sedation, unconsciousness, and anesthesia. On SBP, time effect was significantly different at the 0.05 level of significance; time and group interaction effect was significantly different at the 0.01 level of significance. On HR, both time effect and group interaction effects were significantly different at the 0.05 level of significance. On RR, no difference was found in both time effect and interaction effect. $\$$ indicates significant difference from baseline. $\$$ indicates significant difference from sedation. $\dagger$ indicates significant difference from unconsciousness. On RR, no difference was found in both time effect and interaction effect.

of BIS vs. AEP, only two correlation coefficients in the sevoflurane group were significant at the 0.05 level of significance. $R=0.66$ when BIS in baseline vs. AEP in the baseline stage, and $r=0.52$ when BIS in the unconsciousness stage vs. AEP in the anesthesia stage. All the others are not significantly correlated (Tables 7 and 8).

Both monitors showed a trend of diminishing level of consciousness with both anesthetic techniques. The index showed good correlation with stage of induction (Table 9), except with AEP when used with sevoflurane which gave a low correlation coefficient of -0.61 and a $95 \%$ CI crossing -0.5 . Results showed that propofol had higher correlations between stage of anesthesia and BIS and AEP than sevoflurane. BIS had higher correlations with depth of anesthesia than AEP (given the prior probabilities for the sedation/ unconsciousness/anesthesia to be 0.5).

Effective concentrations EC5, EC50, and EC95 referred to drug concentration at which $5 \%, 50 \%$, and $95 \%$ of the patients, respectively, reached the predefined end point. EC5, EC50, and EC95 of predicted blood and effect-site propofol and inspired and end-tidal sevoflurane as well as BIS and AEP values at sedation, unconsciousness, and anesthesia and their sensitivity, specificity, and $P_{K}$ values are shown in Tables 10-12, respectively. Effect-site propofol concentration had a smaller $95 \%$ CI of EC50 than that of blood at all stages from sedation to anesthesia. This difference is not noticed between inspired and end-tidal sevoflurane. BIS gave similar 95\% CI of EC50 with propofol and sevoflurane at sedation and unconsciousness, but a range of smaller values with sevoflurane at anesthesia. For AEP, propofol always showed a range of smaller values from sedation to anesthesia.
$P_{K}$ is the probability that the indicator values of the data points predict correctly which of the data points are the lighter (or deeper). A value of $P_{K}=0.5$ means that the indicator correctly predicts the anesthetic depths only $50 \%$ of the time, i.e., no better than a 50:50 chance. A value of $P_{K}=1$ means that the indicator predicts the anesthetic depths correctly $100 \%$ of the time.

3.3.3. Predicting Power. Table 13 shows the $P_{K}$ for depth of anesthesia measured by the two monitors, BIS and AEP with different anesthetic techniques, propofol and sevoflurane. BIS had good $P_{K}$ values with both propofol and sevoflurane with both above 0.8 , and the $P_{K}$ with propofol was better than that with sevoflurane. On the contrary, AEP did not have good $P_{K}$ values, especially with sevoflurane. The $P_{K}$ values with BIS are significantly better than those with sevoflurane. The prediction powers of BIS and AEP do not seem as good as some papers mentioned $\left(P_{K}>0.9\right)$.

\section{Discussion}

In this study, we investigated the usefulness and consistency of two anesthetic depth monitors, BIS and AEP with different anesthetic techniques, propofol intravenous anesthesia and sevoflurane inhalational anesthesia. BIS and AEP are two popular anesthetic depth monitors. It is important for them to perform consistently with different anesthetic techniques.

EC50 is analogous to the concept of minimum alveolar concentration for volatile anesthetics and is defined as the concentration of an i.v. anesthetic agent at which $50 \%$ of the 
TABle 4: Descriptive statistics of drug concentrations, BIS, and AEP at different stages of induction.

\begin{tabular}{|c|c|c|c|c|c|c|c|c|}
\hline \multirow{2}{*}{$\begin{array}{l}\text { Mean } \pm \text { SD, } \\
\text { median (range) } \\
\text { Stage }\end{array}$} & \multicolumn{2}{|c|}{$\begin{array}{c}\text { Predicted blood } \\
\text { concentration } \mu \mathrm{g} \cdot \mathrm{ml}^{-1}\end{array}$} & \multicolumn{2}{|c|}{$\begin{array}{l}\text { Effect-site concentration } \\
\qquad \mu \mathrm{g} \cdot \mathrm{ml}^{-1}\end{array}$} & \multicolumn{2}{|c|}{ BIS } & \multicolumn{2}{|c|}{ AEP } \\
\hline & Propofol & Sevoflurane & Propofol & Sevoflurane & Propofol & Sevoflurane & Propofol & Sevoflurane \\
\hline Baseline & - & - & - & - & $\begin{array}{c}96.5 \pm 3.19 \\
97.5[84-98]\end{array}$ & $\begin{array}{c}96.6 \pm 2.0197 \\
{[90-98]}\end{array}$ & $\begin{array}{c}83.0 \pm 10.682 \\
{[58-99]}\end{array}$ & $\begin{array}{c}79.4 \pm 12.64 \\
78.5[48-99]\end{array}$ \\
\hline Sedation & $\begin{array}{c}2.0 \pm 0.442 \\
{[1.5-3.0]}\end{array}$ & $\begin{array}{c}2.7 \pm 0.722 .6 \\
{[1.2-3.8]}\end{array}$ & $\begin{array}{c}1.2 \pm 0.29 \\
1.2 \\
{[0.7-1.7]}\end{array}$ & $\begin{array}{c}1.6 \pm 0.53 \\
1.55 \\
{[0.6-2.45]}\end{array}$ & $\begin{array}{c}81.2 \pm 6.3682 \\
{[64-93]}\end{array}$ & $\begin{array}{c}83.8 \pm 14.63 \\
86.5[41-98]\end{array}$ & $\begin{array}{l}58.1 \pm 23.10 \\
60[20-95]\end{array}$ & $\begin{array}{c}63.1 \pm 19.45 \\
65.5[25-99]\end{array}$ \\
\hline Unconsciousness & $\begin{array}{c}3.5 \pm 0.83 \\
3.5 \\
{[2.0-5.5]}\end{array}$ & $\begin{array}{c}3.4 \pm 0.623 .4 \\
{[2.4-4.6]}\end{array}$ & $\begin{array}{c}2.4 \pm 0.62 \\
2.4 \\
{[1.2-3.7]}\end{array}$ & $\begin{array}{c}2.3 \pm 0.68 \\
2.25 \\
{[1.3-3.95]}\end{array}$ & $\begin{array}{c}58.0 \pm 10.33 \\
56.5[40-74]\end{array}$ & $\begin{array}{c}59.2 \pm 19.1860 \\
{[19-86]}\end{array}$ & $\begin{array}{c}34.1 \pm 14.45 \\
30[10-55]\end{array}$ & $\begin{array}{l}51.7 \pm 20.02 \\
46[22-89]\end{array}$ \\
\hline Anesthesia & $\begin{array}{c}4.2 \pm 0.984 \\
{[2.5-6.0]}\end{array}$ & $\begin{array}{c}4.1 \pm 0.87 \\
3.95 \\
{[2.6-5.95]}\end{array}$ & $\begin{array}{c}3.2 \pm 0.81 \\
3.25 \\
{[1.7-4.9]}\end{array}$ & $\begin{array}{c}3.0 \pm 0.793 .1 \\
{[1.7-4.25]}\end{array}$ & $\begin{array}{c}47.8 \pm 8.67 \\
46.5[36-66]\end{array}$ & $\begin{array}{c}41.05 \pm 16.05 \\
40[14-72]\end{array}$ & $\begin{array}{l}17.78 \pm 5.97 \\
17.5[8-29]\end{array}$ & $\begin{array}{c}38.7 \pm 22.97 \\
30.5[12-83]\end{array}$ \\
\hline
\end{tabular}

TABle 5: BIS and AEP vs. propofol.

\begin{tabular}{|c|c|c|c|c|c|c|c|c|c|}
\hline \multirow{3}{*}{\multicolumn{2}{|c|}{ Propofol }} & \multicolumn{8}{|c|}{ Correlation coefficient, $r$} \\
\hline & & \multicolumn{4}{|c|}{ BIS } & \multicolumn{4}{|c|}{ AEPi } \\
\hline & & Base & Sedation & Unconc & Anes & Base & Sedation & Unconc & Anes \\
\hline \multirow{3}{*}{ Pred } & Sedat & 0.21 & -0.06 & $-0.50^{* *}$ & -0.02 & -0.22 & 0.08 & 0.24 & 0.34 \\
\hline & Unconc & 0.40 & 0.27 & -0.34 & -0.12 & -0.17 & 0.19 & 0.29 & $0.56^{* *}$ \\
\hline & Anesthesia & 0.44 & 0.30 & $-0.49^{* *}$ & -0.35 & -0.14 & 0.15 & 0.33 & 0.43 \\
\hline \multirow{3}{*}{ Eff } & Sedat & 0.22 & 0.09 & -0.30 & -0.31 & $-0.53^{* *}$ & 0.08 & 0.10 & 0.35 \\
\hline & Unconc & 0.42 & 0.27 & -0.26 & -0.16 & -0.23 & 0.09 & 0.22 & $0.56^{* *}$ \\
\hline & Anesthesia & 0.43 & 0.33 & $-0.45^{* *}$ & -0.35 & -0.25 & 0.05 & 0.20 & 0.39 \\
\hline
\end{tabular}

** Significantly different from $r=0$ at the 0.05 level. $r=1$ or -1 means perfect correlation. $r=0$ means no correlation.

TABLE 6: BIS and AEP vs. sevoflurane.

\begin{tabular}{|c|c|c|c|c|c|c|c|c|c|}
\hline \multirow{3}{*}{\multicolumn{2}{|c|}{ Sevoflurane }} & \multicolumn{8}{|c|}{ Correlation coefficient, $r$} \\
\hline & & \multicolumn{4}{|c|}{ BIS } & \multicolumn{4}{|c|}{ AEPi } \\
\hline & & Base & Sedation & Unconc & Anes & Base & Sedation & Unconc & Anes \\
\hline \multirow{3}{*}{ Pred } & Sedat & -0.11 & -0.19 & -0.14 & -0.17 & 0.01 & -0.02 & 0.24 & 0.26 \\
\hline & Unconc & 0.04 & 0.15 & -0.003 & -0.07 & -0.03 & -0.10 & 0.05 & 0.04 \\
\hline & Anes & 0.07 & 0.05 & -0.10 & -0.25 & -0.12 & -0.11 & -0.01 & -0.03 \\
\hline \multirow{3}{*}{ Eff } & Sedat & -0.21 & -0.25 & -0.16 & -0.33 & -0.24 & -0.23 & 0.10 & 0.08 \\
\hline & Unconc & -0.19 & -0.03 & -0.13 & -0.09 & -0.22 & -0.22 & -0.05 & -0.10 \\
\hline & Anes & -0.05 & 0.04 & -0.01 & -0.18 & -0.09 & -0.01 & 0.09 & -0.00 \\
\hline
\end{tabular}

TABLE 7: Correlation analysis of BIS vs. AEPi in the propofol group.

\begin{tabular}{|c|c|c|c|c|c|}
\hline \multirow{2}{*}{\multicolumn{2}{|c|}{ Propofol }} & \multicolumn{4}{|c|}{$\begin{array}{c}\text { Correlation coefficient, } r \\
\text { BIS }\end{array}$} \\
\hline & & Base & Sedation & Unconc & Anes \\
\hline \multirow{4}{*}{ AEPi } & Base & -0.10 & 0.04 & -0.10 & -0.001 \\
\hline & Sedation & 0.22 & 0.40 & 0.32 & -0.01 \\
\hline & Unconc & 0.23 & 0.25 & 0.37 & 0.27 \\
\hline & Anesthesia & 0.17 & 0.14 & 0.30 & 0.29 \\
\hline
\end{tabular}


TABLE 8: Correlation analysis of BIS vs. AEPi in the sevoflurane group.

\begin{tabular}{|c|c|c|c|c|c|}
\hline \multirow{2}{*}{\multicolumn{2}{|c|}{ Sevoflurane }} & \multicolumn{4}{|c|}{$\begin{array}{c}\text { Correlation coefficient, } r \\
\text { BIS }\end{array}$} \\
\hline & & Base & Sedation & Unconc & Anes \\
\hline \multirow{4}{*}{ AEPi } & Base & $0.66^{* *}$ & 0.27 & 0.18 & 0.14 \\
\hline & Sedation & 0.29 & 0.23 & 0.17 & 0.18 \\
\hline & Unconc & 0.33 & 0.26 & 0.38 & 0.17 \\
\hline & Anesthesia & 0.16 & 0.12 & $0.52^{* *}$ & 0.21 \\
\hline
\end{tabular}

${ }^{* *}$ Significant different from $r=0$ at the 0.05 level. $r=1$ or -1 means perfect correlation. $r=0$ means no correlation.

TABle 9: Correlation of depth of anesthesia (4 stages, including baseline) vs. BIS and AEP.

\begin{tabular}{lccc}
\hline & \multicolumn{2}{c}{ Spearman correlation coefficient, $r[95 \% \mathrm{CI}]$} & $P$ value $\left(H_{0}: s_{\text {sevo }}=s_{\text {prop }}\right)$ \\
\hline BIS & Propofol & Sevoflurane & $<0.05^{* *}$ \\
AEP & $-0.92^{* *}[-0.87,-0.95]$ & $-0.86^{* *}[-0.79,-0.91]$ & $<0.05^{* *}$ \\
$P$ value $\left(H_{0}: s_{\text {BIS }}=s_{\text {AEP }}\right)$ & $-0.80^{* *}[-0.71,-0.87]$ & $-0.61^{* *}[-0.45,-0.73]$ & $<0.05^{* *}$ \\
\hline
\end{tabular}

Standard errors (SE) for the above $s$ are 0.11 . ${ }^{* *}$ Significantly different from $s=0$ at 0.05 .

patients will not move or respond to skin incision. This clinically useful concept allows prediction of propofol concentration in the blood and at the effect site $[25,26]$.

We defined the anesthesia stage as when the patient showed no gross purposeful movement to tetanic stimulation of the ulnar nerve, which was easy to perform and had the advantage over skin incision as a repeatable stimulus. A study showed no significant difference between the effective concentration of propofol which prevented half of the patients to move $\left(\mathrm{EC}_{50}\right)$ at tetanic stimulation and that at skin incision in somatic response, but significant differences in haemodynamic response $[25,26]$. Tetanic stimulation was useful in this study as a reproducible and repeatable stimulus at different propofol and sevoflurane concentrations. Similar to the results from Milne's group, the range of effect-site concentrations to include $90 \%$ of patients (EC5-EC95) was smaller than the predicted blood concentration range and hence a more useful figure to guide propofol administration [27]. Similarly, in the sevoflurane group, the range of endtidal concentrations was smaller than the inspired, but to a lesser extent. Both monitors had distinctly different EC50s with small 95\% CI. BIS had similar EC50s with both propofol and sevoflurane, but AEP showed different values between the two anesthetic techniques.

In this study, $90 \%$ of the patients were sedated at a BIS value between 90 and 71 with propofol or between 100 and 60 with sevoflurane. This indicates that BIS is therefore better at predicting sedation with propofol. AEP showed very wide range of values in order to induce $90 \%$ of the patients at sedation with both propofol (AEP value range 100-11) and sevoflurane (AEP value range 96-27), and therefore, AEP did not seem to be useful in guiding sedation. At unconsciousness, BIS showed a smaller range with propofol (BIS value range 77-37) than with sevoflurane (BIS value range 93-23), which might again indicate that BIS performs better with propofol. AEP showed a wide range with both propofol (AEP value range 61-4) and sevoflurane (AEP value range 85-12) at unconsciousness. At anesthesia, BIS again had a smaller range with propofol (BIS value range 61-31) than with sevoflurane (BIS value range 67-11). AEP showed a narrow range with propofol (AEP value range 28-6) but a wide one with sevoflurane (AEP value range 75-0). BIS appeared to be a good indicator of depth of anesthesia with propofol, which was reflected by the high $P_{K}$ value of 0.91 . Anesthetic seemed to have an effect on performance of the monitors, particularly with AEP monitor. BIS overall performed well with both anesthetic techniques, i.v. propofol and inhalational sevoflurane, but with a higher $P_{K}$ with propofol. AEP showed poorer performance than BIS in our study. With a $P_{K}$ of 0.56 with sevoflurane, AEP became doubtful as an anesthetic depth monitor which means the prediction powers of BIS and AEP do not seem as good as some papers mentioned [21, 22, 28, 29]. Considering the difference results between this study and previous ones, different protocols of studies might be the reason [22, 28-30]. We use detected more drug concentrations at more time points with more accurate statistical methods, but we still think we need more studies to verify the results. And this result might remind the clinicians that both BIS and AEP are not as reliable as they thought.

In summary, we obtained good EC50 with both monitors, but the index variation was affected by the anesthetic technique. The performance of the anesthetic depth monitors was better when propofol was used. Very wide variation was found in the combination of AEP and sevoflurane $[22,25,31-33]$. It seems the monitors are at best at giving the EC50, at which there is a $50 \%$ chance that the patient has reached the end point, and we have not yet found an anesthetic depth monitor that has high sensitivity and specificity and not affected by the anesthetic technique. 


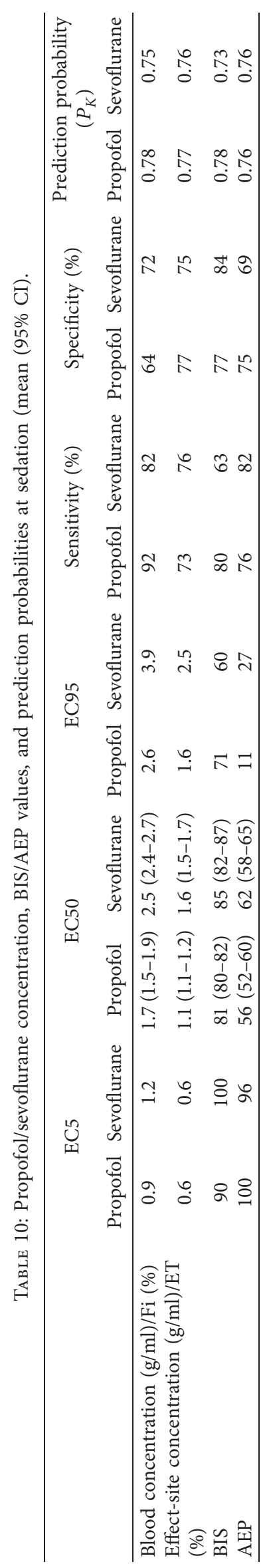




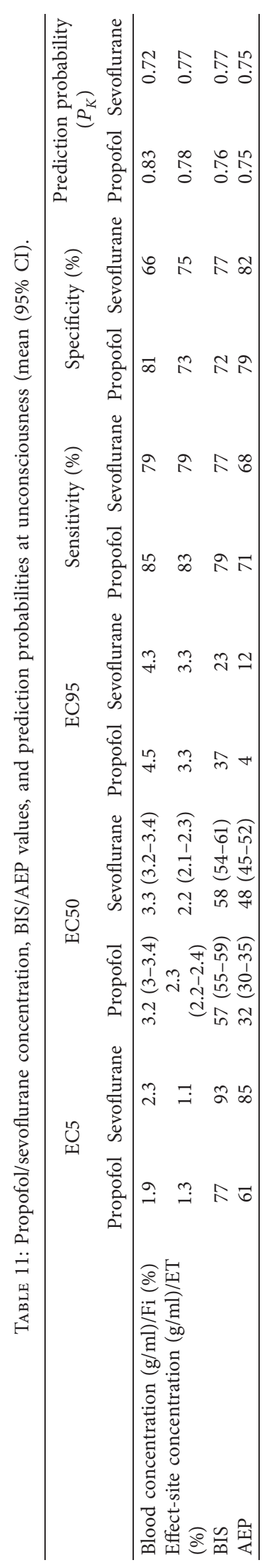




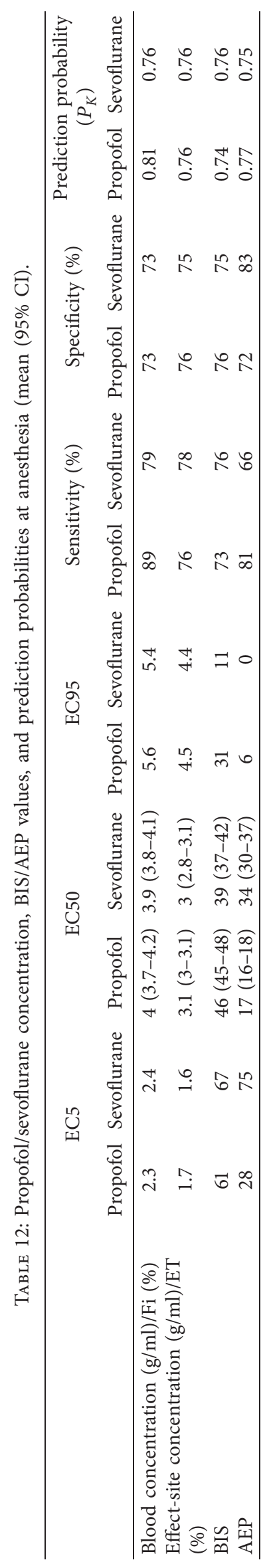


TABle 13: Prediction probability $P_{K}$ for the depth of anesthesia (considering 4 stages including baseline).

\begin{tabular}{lccc}
\hline & $P_{K}$ (SE) $[P$ values for testing & $P$ value $\left[H_{0}:\right.$ \\
& BIS & AEP & $\left.P_{K}=0.5\right]$ \\
KBIS & $\left.=P_{\text {KAEP }}\right]$ \\
\hline \multirow{2}{*}{ Propofol } & $0.9117(0.0147)$ & $0.7504(0.0238)$ & \\
& {$\left[P<0.0001^{* *}\right]$} & {$\left[P<0.0001^{* *}\right]$} & $<0.0001^{* *}$ \\
Sevoflurane & $0.8233(0.0182)$ & $0.5629(0.0391)$ & \\
& {$\left[P<0.0001^{* *}\right]$} & {$\left[P<0.0001^{* *}\right]$} & $<0.0001^{* *}$ \\
\hline
\end{tabular}

${ }^{* *}$ Significantly different from $s=0$ at 0.05 .

\section{Data Availability}

All the underlying data supporting the results of this study can be found in IRB of Second Affiliated Hospital of Dalian Medical University.

\section{Disclosure}

Haitao Yang and Guan Wang are the co-first authors.

\section{Conflicts of Interest}

The authors declare that there are no conflicts of interest.

\section{Authors' Contributions}

Haitao Yang and Guan Wang contributed equally to this work.

\section{Acknowledgments}

This study was supported by the National Natural Science Foundation of China (no. H81471373).

\section{References}

[1] S. R. Tasbihgou, M. F. Vogels, and A. R. Absalom, "Accidental awareness during general anaesthesia-a narrative review," Anaesthesia, vol. 73, no. 1, pp. 112-122, 2018.

[2] M. Graham, A. M. Owen, K. Çipi, C. Weijer, and L. Naci, "Minimizing the harm of accidental awareness under general anesthesia," Anesthesia \& Analgesia, vol. 126, no. 3, pp. 1073-1076, 2018.

[3] J. W. Sleigh, K. Leslie, A. J. Davidson et al., "Genetic analysis of patients who experienced awareness with recall while under general anesthesia," Anesthesiology, vol. 131, no. 5, pp. 974-982, 2019.

[4] H. Yu and D. Wu, "Effects of different methods of general anesthesia on intraoperative awareness in surgical patients," Medicine, vol. 96, no. 42, p. e6428, 2017.

[5] S. Devroe, M. Van De Velde, and S. Rex, "General anesthesia for caesarean section," Current Opinion in Anaesthesiology, vol. 28, no. 3, pp. 240-246, 2015.

[6] P. Bischoff, I. Rundshagen, and G. Schneider, "Unerwünschte wachphänomene ("awareness") während allgemeinanästhesie,” Der Anaesthesist, vol. 64, no. 10, pp. 732-739, 2015.

[7] M. A. Earley, L. T. Pham, and M. M. April, "Scoping review: awareness of neurotoxicity from anesthesia in children in otolaryngology literature," The Laryngoscope, vol. 127, no. 8, pp. 1930-1937, 2017.
[8] M. Cascella, R. Fusco, D. Caliendo et al., "Anesthetic dreaming, anesthesia awareness and patient satisfaction after deep sedation with propofol target controlled infusion: a prospective cohort study of patients undergoing day case breast surgery," Oncotarget, vol. 8, no. 45, pp. 79248-79256, 2017.

[9] G. Ratnayake and V. Patil, "General anaesthesia during caesarean sections," Current Opinion in Obstetrics and Gynecology, vol. 31, no. 6, pp. 393-402, 2019.

[10] S. D. Bergese, A. A. Uribe, E. G. Puente et al., "A prospective, multicenter, single-blind study assessing indices of SNAP II versus BIS VISTA on surgical patients undergoing general anesthesia," JMIR Research Protocols, vol. 6, no. 2, p. e15, 2017.

[11] C. M. Schulz, V. Krautheim, A. Hackemann, M. Kreuzer, E. F. Kochs, and K. J. Wagner, "Situation awareness errors in anesthesia and critical care in 200 cases of a critical incident reporting system," BMC Anesthesiology, vol. 16, no. 4, 2016.

[12] M. H. Chiang, S. C. Wu, S. W. Hsu, and J. C Chin, "Bispectral Index and non-bispectral Index anesthetic protocols on postoperative recovery outcomes," Minerva Anestesiologica, vol. 84, no. 2, pp. 216-228, 2018.

[13] J. Lee, C. Park, and S. Kim, “Awareness during general anesthesia despite simultaneous bispectral index and end-tidal anesthetic gas concentration monitoring," Yeungnam University Journal of Medicine, vol. 36, no. 1, pp. 50-53, 2019.

[14] B. Altiparmak, N. Celebi, O. Canbay, M. K. Toker, B. Kılıçarslan, and Ü. Aypar, "Effect of magnesium sulfate on anesthesia depth, awareness incidence, and postoperative pain scores in obstetric patients. a double-blind randomized controlled trial," Saudi Medical Journal, vol. 39, no. 6, pp. 579-585, 2018.

[15] S. R. Lewis, M. W. Pritchard, L. J. Fawcett, and Y. Punjasawadwong, "Bispectral index for improving intraoperative awareness and early postoperative recovery in adults," Cochrane Database of Systematic Reviews, vol. 9, no. 9, Article ID 9CD003843, 2019.

[16] T. Lahtinen, J. Seppälä, T. Viren, and K. Johansson, "Experimental and analytical comparisons of tissue dielectric constant (TDC) and bioimpedance spectroscopy (BIS) in assessment of early arm lymphedema in breast cancer patients after axillary surgery and radiotherapy," Lymphatic Research and Biology, vol. 13, no. 3, pp. 176-185, 2015.

[17] I. Karaca, F. Eren Akcil, O. Korkmaz Dilmen, G. Meyanci Koksal, and Y. Tunalı, "The effect of BIS usage on anaesthetic agent consumption, haemodynamics and recovery time in supratentorial mass surgery," Turkish Journal of Anesthesia and Reanimation, vol. 42, no. 3, pp. 117-122, 2014.

[18] J. Shepherd, J. Jones, G. Frampton, J. Bryant, L. Baxter, and K. Cooper, "Clinical effectiveness and cost-effectiveness of depth of anaesthesia monitoring (E-entropy, bispectral index and narcotrend): a systematic review and economic evaluation," Health Technology Assessment, vol. 17, no. 34, pp. 1-264, 2013.

[19] M. Cornella, A. Bendixen, S. Grimm et al., "Spatial auditory regularity encoding and prediction: human middle-latency and long-latency auditory evoked potentials," Brain Research, vol. 1626, pp. 162621-162630, 2015.

[20] L. Li and Q. Gong, "The early component of middle latency auditory-evoked potentials in the process of deviance detection," Neuroreport, vol. 27, no. 10, pp. 769-773, 2016.

[21] Y. Punjasawadwong, W. Chau-In, M. Laopaiboon, S. Punjasawadwong, and P. Pin-On, "Processed electroencephalogram and evoked potential techniques for amelioration of postoperative delirium and cognitive dysfunction 
following non-cardiac and non-neurosurgical procedures in adults," Cochrane Database of Systematics Review, vol. 5, no. 5, Article ID 5CD011283, 2018.

[22] K. Szostakiewicz, Z. Rybicki, and D. Tomaszewski, "Noninstrumental clinical monitoring does not guarantee an adequate course of general anesthesia. a prospective clinical study," Biomedical Papers, vol. 162, no. 3, pp. 198-205, 2018.

[23] M. Tacke, E. F. Kochs, M. Mueller et al., "Machine learning for a combined electroencephalographic anesthesia index to detect awareness under anesthesia," PLoS One, vol. 15, no. 8, Article ID e0238249, 2020.

[24] B. Huang, F. Liang, L. Zhong et al., "Latency of auditory evoked potential monitoring the effects of general anesthetics on nerve fibers and synapses," Scientific Reports, vol. 5, no. 1, Article ID 12730, 2015.

[25] S. Li, F. Yu, H. Zhu, Y. Yang, L. Yang, and J. Lian, “The median effective concentration (EC50) of propofol with different doses of fentanyl during colonoscopy in elderly patients," BMC Anesthesiology, vol. 16, p. 24, 2016.

[26] Y.-C. Shang and B.-Z. Chen, "Propofol EC50: an effect of luteal phase core temperature differences?," British Journal of Anaesthesia, vol. 114, no. 3, p. 526, 2015.

[27] S. E. Milne, A. Troy, M. G. Irwin, and G. N. C. Kenny, "Relationship between bispectral index, auditory evoked potential index and effect-site EC50 for propofol at two clinical end-points $\dagger$," British Journal of Anaesthesia, vol. 90, no. 2, pp. 127-131, 2003.

[28] B. Horn, S. Pilge, E. F. Kochs, G. Stockmanns, A. Hock, and G. Schneider, "A combination of electroencephalogram and auditory evoked potentials separates different levels of anesthesia in volunteers," Anesthesia \& Analgesia, vol. 108, no. 5, pp. 1512-1521, 2009.

[29] C. Luo and W. Zou, "Cerebral monitoring of anaesthesia on reducing cognitive dysfunction and postoperative delirium: a systematic review," Journal of International Medical Research, vol. 46, no. 10, pp. 4100-4110, 2018.

[30] C. Jeleazcov, G. Schneider, M. Daunderer, B. Scheller, J. r. Sch??ttler, and H. Schwilden, "The discriminant power of simultaneous monitoring of spontaneous electroencephalogram and evoked potentials as a predictor of different clinical states of general anesthesia," Anesthesia \& Analgesia, vol. 103, no. 4, pp. 894-901, 2006.

[31] M. Zaballos, E. Bastida, S. Agusti, M. Portas, C. Jiménez, and M. López-Gil, "Effect-site concentration of propofol required for LMA-supreme insertion with and without remifentanil: a randomized controlled trial," BMC Anesthesiology, vol. 15, p. 131, 2015.

[32] J. Y. Yoo, H. J. Kwak, K. C. Lee, G. W. Kim, and J. Y. Kim, "Predicted EC50 and EC95 of remifentanil for smooth removal of a laryngeal mask airway under propofol anesthesia," Yonsei Medical Journal, vol. 56, no. 4, pp. 1128-1133, 2015.

[33] L. Laaksonen, M. Kallioinen, J. Långsjö et al., "Comparative effects of dexmedetomidine, propofol, sevoflurane, and S-ketamine on regional cerebral glucose metabolism in humans: a positron emission tomography study," British Journal of Anaesthesia, vol. 121, no. 1, pp. 281-290, 2018. 